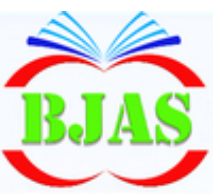

ISSN $1814-5868$
Available online at http://bjas.bajas.edu.iq https://doi.org/10.37077/25200860.2021.34.1.20 College of Agriculture, University of Basrah

\title{
Short Notes \\ First Report of Alternaria arborescens Causing Early Blight on Tomato in Iraq
}

Basrah J. Agric. Sci., 34(1): 230-232, 2021

Nisreen J. Razak, and Mohammed H. Abass*

\author{
Plant Protection Department, College of Agriculture, University of Basrah, Basrah, Iraq \\ *Correspondence, author email: dr.mha24@yahoo.co.uk \\ First author email: nisreenjafar@yahoo.com
}

Received $5^{\text {th }}$ January 2021; Accepted $10^{\text {th }}$ February 2021; Available online 27 February 2021

\begin{abstract}
In this paper, the isolation of the fungal species Alternaria arborescens was done from symptomatic tomato leaves and diagnosed morphologically and molecularly using ITS primers. Subsequently, pathogenicity determination was achieved for the diagnosed fungal species on tomato plant. It's noteworthy, this work on A. arborescens was not previously recorded as a potential pathogen on the shoot system of tomato in Iraq.

Keywords: Alternaria arborescens, Lycopersicon esculentum Mill, morphology, pathogenicity, phylogenetic analysis.
\end{abstract}

Tomato plants (Lycopersicon esculentum Mill) diagnosed by different disease symptoms including leaf spot; lesion and early blight diseases caused by several pathogenic fungi which were examined in the fourth quarter of 2019 in greenhouses in Basra Governorate, Iraq. The examination was overall for all the symptoms that presented in relevant farms to make a comprehensive detection on the fungal pathogens isolated symptomatic tomato plant; but particularly this research focused on identification of certain Alternaria species (Alternaria arborescens) causing early blight disease. A. arborescens isolates are effective pathogen in a cool weather of $10-25^{\circ} \mathrm{C}$ and fairly high humidity which consider a potential pathogen on tomato plants. Primarily, to identify the pathogen, phenotypical identity of the isolates was adopted on PDA medium and under standardized conditions (Fig. 1) as it was found that it matches somewhat what was mentioned in a number of relevant literature (Simmons \& Roberts, 1993; Rao et al., 2017; Ramezani et al., 2019). The colony was usually dark olive gray with white margin. Conidia were ovoid in shape with dark brown colour (11 to $33 \times 6.0$ to $14.0 \mu \mathrm{m}$ ). Conidiophores had narrow and spire configuration, 50 to $200 \times 2.5 \mu \mathrm{m}$. 


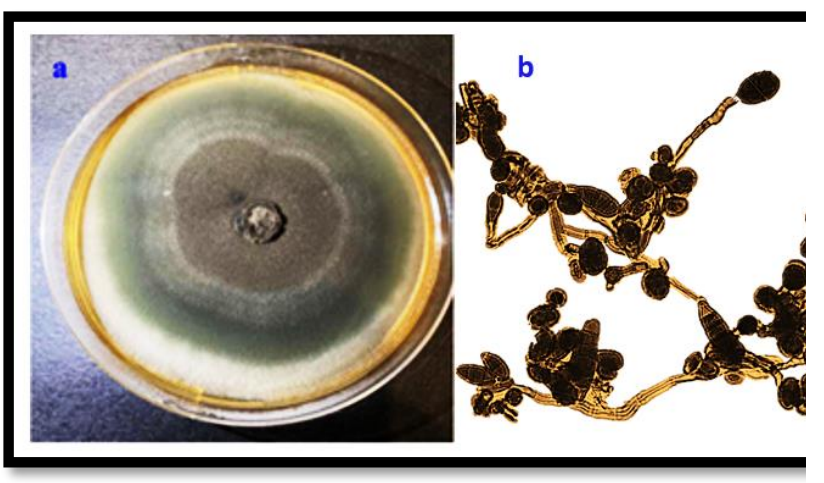

Fig. (1): Morphological traits of $A$. arborescens (a) colony morphology on PDA after 7 days, (b) conidia and surface decorations. Scale bar $=10 \mu \mathrm{m}$.

It is worth noting that the comparison of phenotypic traits among reference literature have not given reliable discrimination; in addition, as it is still confusing in the phylogenetic description among some of Alternaria species especially in comparison among A. alternata, A. arborescens and $A$. tenuissima isolates (Kahl et al., 2015). In addition, the internal transcribed spacer (ITS) region from relevant isolate had amplified adopting primers ITS1 and ITS4 and sequenced (GenBank Accession No. MZ027641). The 560-bp amplicons had 98\% identity to $A$. arborescens (GenBank Accession No. MT367636.1). Phylogenetic analysis gave a well identification that the isolated fungus is A. arborescens.

Koch's postulates were carried out on the tomato seedlings with full-grown leaves at the age of 6 weeks at greenhouse conditions $\left(15-25^{\circ} \mathrm{C}\right.$ with high relative humidity; Ramezani et al., 2019). Five tomato seedlings were inoculated via the pathogen $\left(1 \times 10^{6}\right.$ spore $\left./ \mathrm{ml}\right)$, where early blight symptoms appeared on the leaves in some seedlings after two weeks (Fig. 2). The symptoms incidence was $40 \%$. This investigation considers as first report of tomato early blight caused by $A$. arborescens in Iraq. It is worth mentioning, recently the tomato early blight caused by $A$. arborescens was also recorded in Iran (Ramezani et al., 2019).

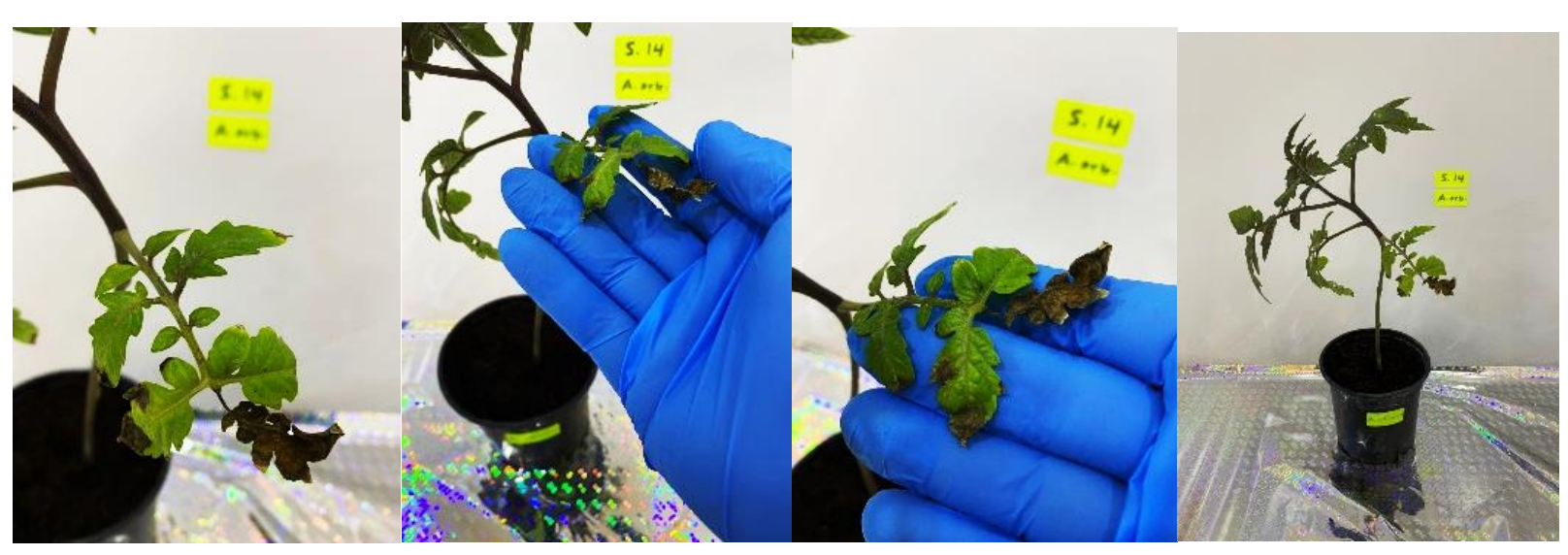

Fig. (2): Tomato early blight symptoms caused by A. arborescens. 
Razak \& Abass / Basrah J. Agric. Sci., 34(1): 230-232, 2020

\section{Acknowledgment}

The authors thank the staff of Basrah Department of Plant Protection, as well all Ministry of Agriculture, Iraq, for their fruitful cooperation in accomplishing research work.

\section{Conflicts of interest}

The authors declare that they have no conflict of interests.

ORCID M. H. Abass: http://orcid.org/0000-00024697-4076

ORCID N. Jafar: https://orcid.org/0000-0003-28117932

\section{References}

Kahl, S. M., Ulrich, A., Kirichenko, A. A., \& Müller, M. E. H. (2015). Phenotypic and phylogenetic segregation of Alternaria infectoria from smallspored Alternaria species isolated from wheat in
Germany and Russia. Journal of applied microbiology, 119, 1637-1650. https://doi.org/10.1111/jam.12951

Ramezani, Y., Taheri, P., \& Mamarabadi, M. (2019). Identification of Alternaria spp. associated with tomato early blight in Iran and investigating some of their virulence factors. Journal of Plant Pathology, 101, 647 -

659.https://doi.org/10.1007/s42161-019-00259-w

Rao, H. Y., Rakshith, D., Harini, B. P., \& Satish, S. (2017). Antimicrobial profiling and molecular identification of Alternaria arborescens CLB12, a myco-endosymbiont inhabiting Combretum latifolium Blume. Journal of Biologically Active Products from Nature, 7, 1-9. https://doi.org/10.1080/22311866.2017.1287592

Simmons, E. G., \& Roberts, R. G. (1993). Alternaria themes and variations (73). Mycotaxon, 48, 109140.

https://www.cabdirect.org/cabdirect/abstract/199 42300558

\section{التسجيل الأول للفطر Alternaria arborescens كمسبب ممرض الى اللفحة المبكرة في نبات الطماطة في العراق كمئ

